\title{
Study of the Fluoridated Adhesive Resin Cement -Fluoride Release, Fluoride Uptake and Acid Resistance of Tooth Structures-
}

\author{
Linlin HAN, Neamat ABU-BAKR, Akira OKAMOTO \\ and Masaaki IWAKU \\ Department of Operative Dentistry and Endodontics, \\ Niigata University Faculty of Dentistry, \\ 5274, Gakkocho-dori 2-bancho, Niigata 951-8514, Japan
}

Received October 15, 2000/Accepted December 22, 2000

\begin{abstract}
The objectives of this study, were to evaluate the fluoride release from fluoridate adhesive resin cement, fluoride uptake into surrounding tooth structures and the effect of their acid resistance. Several specimens were prepared using a plastic ring mould, from extracted human premolars, and prepared from enamel and dentin of the central area of the buccal surface of bovine teeth. The fluoride release rate of fluoridate adhesive resin cement (PN 200) per day was higher than other materials during the 7-day study period. Fluoride released and fluoride uptake by tooth structures was higher in the fluoridate adhesive resin cement. WDX analysis showed the fluoride concentration on dentin contact area was higher than that of enamel after 60 days of immersion in deionized water. The calcium release values were similar for enamel and dentin plates in the various test materials. The present findings indicated the important enhancement of tooth structure acid resistance by fluoridate material.
\end{abstract}

Key words : Fluoridated adhesive resin cement, Fluoride release, Acid resistance

\section{INTRODUCTION}

Fluoride-releasing restorative materials may prevent the development of secondary carious lesions at the restoration-tooth interface and may help to prevent the initiation of the carious process in adjacent tooth tissue ${ }^{1)}$. Fluoride released from restorations is a clinically safe method for prevention of caries because the presence of fluoride increases the acid resistance of the adjacent tooth and exerts a cariostatic effect $^{1-4)}$. Although used as restorative materials, cavity liners and luting cements, early glass ionomer materials showed unfavorable physical properties such as poor wear resistance, brittleness, and sensitivity to moisture contamination ${ }^{5)}$. To overcome these disadvantages, resin-modified glass ionomer cement was developed ${ }^{5)}$. Despite the presence of the resin component, studies have demonstrated various levels of fluoride release and caries inhibition using these improved materials ${ }^{6)}$. Recently, resin composites were selected as restorative materials and the release of fluoride from these materials was evaluated ${ }^{7-8)}$. At first, fluoride was incorporated into the resin by simply mixing the fluoride compound in the resin composite. The fluoride compounds readily decomposed by dissolution into an aqueous phase (saliva) resulting in a significant decrease in their physical properties with time ${ }^{9)}$. 
Thus, manufacturers have tried to develop a true fluoride-releasing composite which does not show any degradation over a long period of time. As a result, various fluoride releasing systems have been developed ${ }^{10)}$. Some products adopted a resin-bound fluoride compound as resin matrix ${ }^{10)}$. Other products used dispersed sparingly soluble fluoride salts as a their inorganic fillers. These fluoride containing composites were developed to release fluoride slowly over an extended period of time. However, unlike glass ionomer cement, the cariostatic effectiveness of fluoride containing composite resin has not been studied intensively. The fluoridate adhesive resin cement is an adhesive materials for metal, composite resin, inlays, crowns and bridges. An advantage of these adhesive materials is the fluoride release. The fluoridated resin cement contains some fluoride sodium $(\mathrm{NaF})$ fillers in the base resin of the cement. Fluoride ion release with the fluoridate sodium filler is possibly easier than fluoridated polymer containing resin-modified sealant or compomer, because sodium dissolves too easy when it comes into contact with water ${ }^{8)}$.

The purpose of this study, was to evaluate the fluoride release from fluoridate adhesive resin cement, fluoride uptake into surrounding tooth structures and the effect of their acid resistance.

\section{MATERIALS AND METHODS}

The materials used in this study were a non-fluoridate composite bonding system (CPB) as a control and test materials: light-cure glass ionomer cement for liner (FLC), fluoridate adhesive resin cement ( $\mathrm{PN} 200$ ) and resin fissure sealant ( $\mathrm{T}-\mathrm{F}$ ) (Table 1).

The following investigations were conducted:

\section{( I ) Fluoride Release}

Samples were prepared using a plastic ring mould (with an internal dimension of 9 $\mathrm{mm}$ diameter and $1 \mathrm{~mm}$ height). The mould with sample material was held between two glass slides and covered with a transparent polyester strip. Materials were manipulated according to the manufaturer instructions. A silk thread was placed so

Table 1 Materials used in this study

\begin{tabular}{llllll}
\hline \multicolumn{1}{c}{ Material } & Code & $\begin{array}{c}\text { Type of } \\
\text { curing }\end{array}$ & Application & Batch No. & Manufacturer \\
\hline $\begin{array}{l}\text { Clearfil Photo } \\
\text { bond }\end{array}$ & CPB & L & Restoration & 11122 & $\begin{array}{l}\text { Kuraray, Osaka } \\
\text { Japan }\end{array}$ \\
Fuji Lining LC & FLC & L & Liner & $\begin{array}{l}\text { P: 261241 } \\
\text { L: } 19124\end{array}$ & $\begin{array}{l}\text { GC, Tokyo } \\
\text { Japan }\end{array}$ \\
Fluorocement & PN200 & L/C* & Luting & PN1330 & $\begin{array}{l}\text { Kuraray, Osaka } \\
\text { Japan }\end{array}$ \\
Teethmate F & T-F & L & $\begin{array}{l}\text { Fissure } \\
\text { Sealent }\end{array}$ & 11122 & $\begin{array}{l}\text { Kuraray, Osaka } \\
\text { Japan }\end{array}$ \\
\hline
\end{tabular}

${ }^{*} \mathrm{~L} / \mathrm{C}$ : light and chemical cure. 
that after the material set it could be used to suspend the sample in the solution. The beakers had tightly fitting lids to prevent evaporation of the solution. Samples were kept in deionized water $(10 \mathrm{ml})$ at a temperature of $37^{\circ} \mathrm{C}$. Standard solutions from sodium fluoride solution with $0.1,1,10$ and $100 \mathrm{ppm}$ were prepared. To the four solutions TISAB III (total ionic strength adjustor and buffer; Orion, Boston, USA) was added in order to obtain a constant background ionic strength. The standard solutions were used to plot the calibration graph. The fluoride release was detected using a fluoride ion selective electrode (9609BN, Orion Model 290A, USA) connected to a microprocessor ion analyzer (Orion model 290A, USA). The test specimen was placed on a nonheating magnetic stirrer (AT1 model AS 1, Kanazawa, Japan), to obtain an even distribution of the fluoride ions. The temperature of the solution was adjusted to $23 \pm 2{ }^{\circ} \mathrm{C}$ in order to compensate for any fluctuation in temperature. The fluoride ion concentration $(\mathrm{ppm})$ of the test solutions were recorded after 1, 7, 30 and 60 days. Five specimens were prepared for each test material.

\section{( II ) Fluoride Uptake by tooth structure}

The specimens were prepared from premolars extracted for orthodontic reasons stored at $4^{\circ} \mathrm{C}$ in isotonic saline no longer than 1 weeks prior to their use. A class $\mathrm{V}$ cavity was prepared on the cervical area of enamel and dentin with a high-speed handpiece and round diamond burs, the cavity depth was about $2 \mathrm{~mm}$. The cavity wall and floors were treated with the conditioner of the test materials. The conditioned cavity was restored with CPB, FLC, PN 200, T-F and light cured for 20 seconds using a visible light unit (LINHTEL-II, Kuraray, Co. LTD, Osaka, Japan). Samples were kept in deionized water $(20 \mathrm{ml})$ at a temperature of $37^{\circ} \mathrm{C}$ after the margins were finished with a fine diamond bur. The specimens were cross-sectioned longitudinally through the center of the cavities with a low speed diamond microcutter (Micro cutter 201, Maruto, Tokyo, JAPAN) after immersion in deionized water for a 60-day period. Specimens were viewed with a electron probe X-ray microanalyzer, WDX type (WDX, EPMA 8705, Shimadzu, Kyoto, Japan) for elemental distribution of fluoride $(\mathrm{F})$, calcium $(\mathrm{Ca})$ and carbon $(\mathrm{C})$ on the cement-enamel or dentin interface.

\section{(III) Effect of Acid Resistance}

Specimens were prepared from enamel and dentin (with dimension of $6 \mathrm{~mm}$ width, 6 $\mathrm{mm}$ length and $3 \mathrm{~mm}$ thickness) obtained from the central area of the buccal surface of bovine incisors. An aluminum foil (about $0.015 \mathrm{~mm}$ thick) as a spacer was placed on the upper surface of the enamel or dentin plate of bovine teeth, and test material specimens were applied on the foil and light-cured using a visible light unit (LINHTEL-II, Kuraray, Co. LTD, Osaka, JAPAN). The foil was removed and an obtruding specimen plate was fixed to enamel or dentin plate with an orthodontic band. The whole surface except the interface between the tooth and specimen were covered by inlay wax. The specimens were placed in deionized water $(20 \mathrm{ml})$ at a temperature of $37^{\circ} \mathrm{C}$ for 60 days, substituting new deionized water at 48-hour 
interval. Subsequently, for demineralization, the specimens were immersed in acetic acid sodium buffer (used acetic acid: $2.4 \mathrm{ml}$, sodium acetate, anhydrous: $3.3 \mathrm{~g}$ dissolved in $200 \mathrm{ml}$ deionized water, and adjusted to $0.2 \mathrm{M}, 4.5 \mathrm{pH}$ ) substituted with new buffer liquid after 1, 3, 6 and 12 hours. In each demineralization solution the calcium concentration was measured with an atomic absorption spectrophotometer (Absorption spectrophotometer 180-50, Hitachi Ltd., Tokyo, JAPAN). Non fluoridate material (CPB) contacting an enamel or dentin plate and immersed in deionized water were used as control groups. For each tested group there were five specimens prepared and each specimen was examined three times.

\section{(IV) Observation of acid resistance zone}

The material used was similar to that of the fluoride uptake test. The specimens were prepared similar to those for the fluoride uptake test. Subsequently, each specimen was immersed in $20 \mathrm{ml}$ acetic acid sodium buffer (acetic acid: $0.24 \mathrm{ml}$, sodium acetate, anhydrous: $0.33 \mathrm{~g}$ dissolved in $20 \mathrm{ml}$ deionized water, and adjusted to $0.2 \mathrm{M}$, $4.5 \mathrm{pH}$ ) for 12 hours for demineralization after storage at a temperature of $37^{\circ} \mathrm{C}$ for 60 days. The samples were cross-sectioned longitudinally through the center of the cavities, and were cut into several thin slices $(60-80 \mu \mathrm{m})$ with a low speed diamond micro-cutter (Micro cutter 201, Maruto, Tokyo, Japan) and observations of cementenamel and dentin cervical marginal area of restorations was conducted using a polarized light microscope.

\section{RESULTS}

\section{( I ) Fluoride Release}

The fluoride release $\left(\mu \mathrm{g} / \mathrm{cm}^{2}\right)$ of the tested materials was shown in Fig. 1 . The fluoride release rate of PN 200 per day was higher than sealant or glass ionomer cement during the 7-day study period. Test materials showed stability and a slow rate of fluoride release after the 7 -day study period.

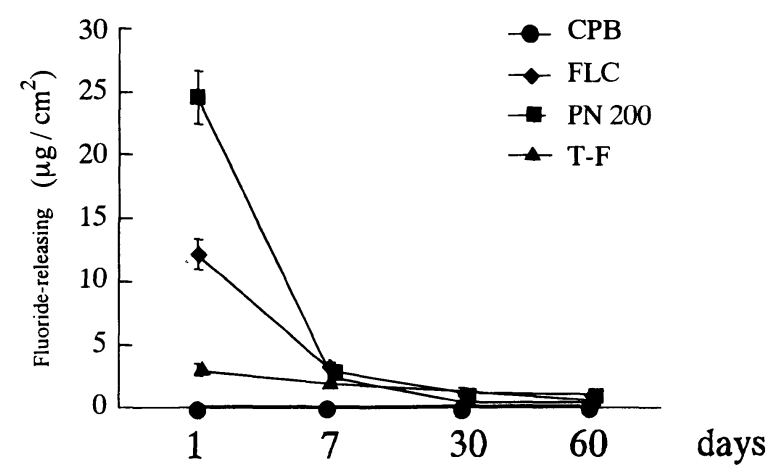

Fig. 1 Fluoride released from fluoridated resin-modified materials in the deionized water at $37^{\circ} \mathrm{C}$ over a 60 -day period. 


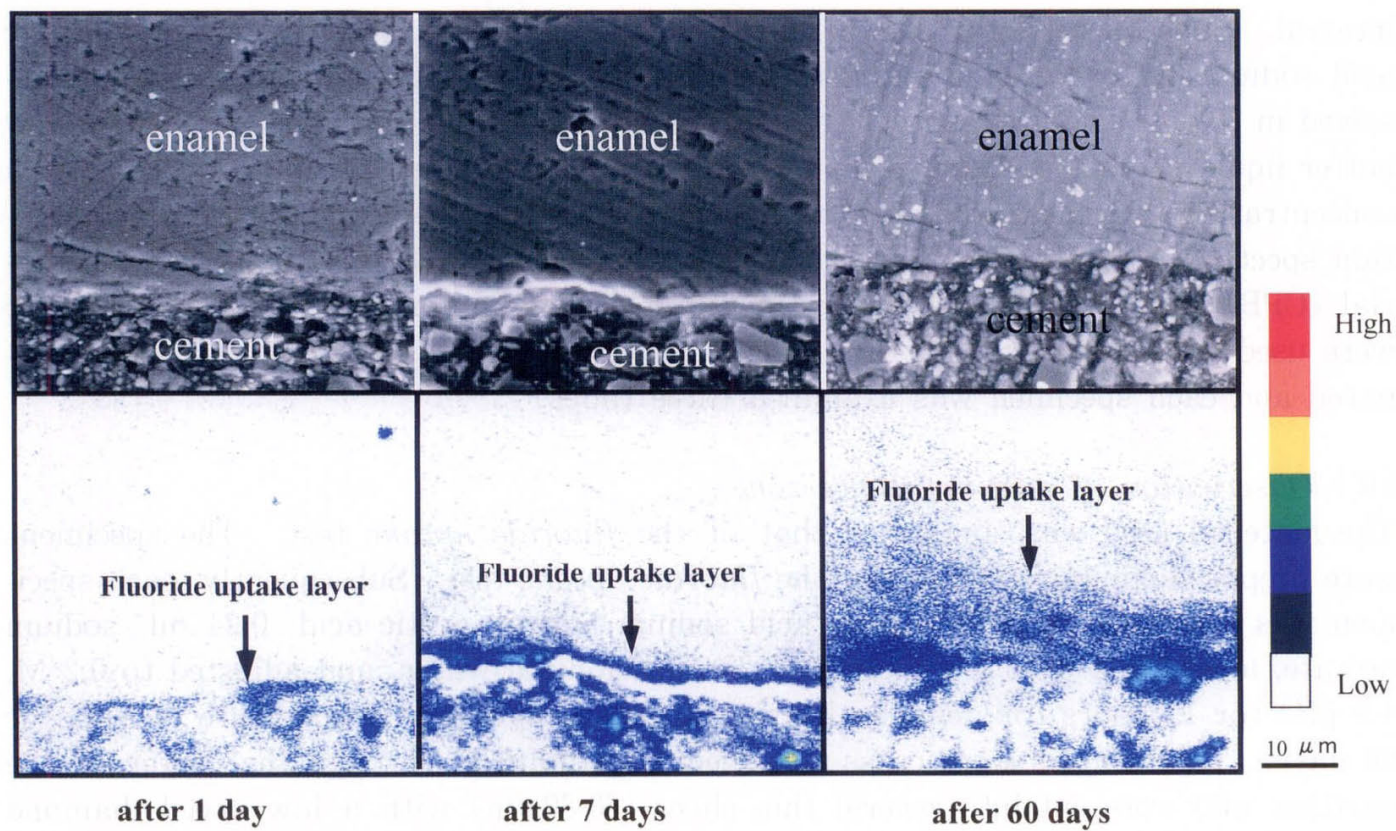

Fig. 2 Fluoride uptake by enamel from PN 200.

Upper: SE Image; Lower: $\mathrm{Fk}_{\alpha}$ with WDX type X-ray microanalyzer, Color bar: $\mathrm{Fk}_{\alpha}$ density.

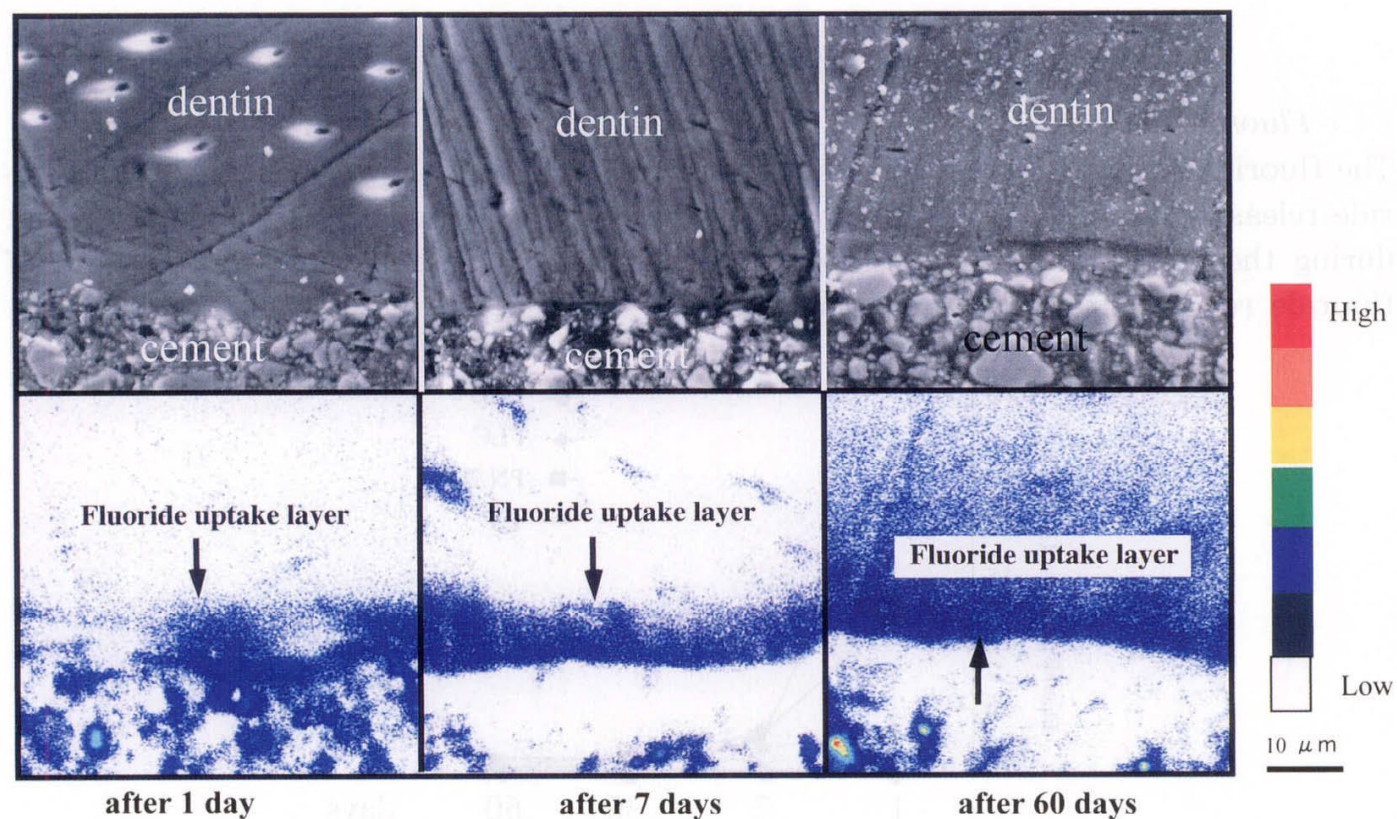

Fig. 3 Fluoride uptake by dentin from PN 200.

Upper: SE Image; Lower: $\mathrm{Fk}_{\alpha}$ with WDX type X-ray microanalyzer, Color bar: $\mathrm{Fk}_{\alpha}$ density. 


\section{( II ) Fluoride Uptake by Tooth Structure}

Figs. 2 and 3 show representative enamel and dentin samples of the WDX type X-ray microanalysis result of the surface (enamel and dentin) contact with fluoridate adhesive resin cement after 1, 7 and 60-day periods (other sample pictures of tested materials are omitted, because observations were similar). WDX analysis showed the fluoride concentration on the dentin contact area was higher than that of enamel after 60 days of immersion, which was higher than after 1, or 7 days. Furthermore, fluoridated adhesive resin cement released fluoride ions, which moved to the enamel or dentin. Consequently, the fluoride concentration was low on the fluoridated resin adhesive cement layer of cement-enamel and dentin contact area (samples of 7 and 60-day periods). For the short period sample, which was 1 day, no fluoride ions moved into tooth structures.

\section{(III) Effect of Acid Resistance}

The findings obtained from this study are presented as the mean of 5 specimens for each group (Figs. 4 and 5, error bars show standard deviations). The mean values presented are in micrograms of calcium released by etchant solution following its application to enamel and dentin previously subjected to any of the investigated conditions. The amount of calcium released served as the criterion for evaluating the effectiveness of the different materials used in treatment of enamel or dentin. PN 200 and FLC released similar amount values of calcium. Calcium released was highest in the samples treated with the conventional composite resin bonding system (CPB). The finding of the amounts of calcium released were similar for enamel and dentin plates in the various test materials.

(IV) Observation of acid resistance zone

Figs. 6 and 7 show polarized light micrographs of enamel and dentin treated with PN 200 (other samples micrographs are omitted because observations were similar).

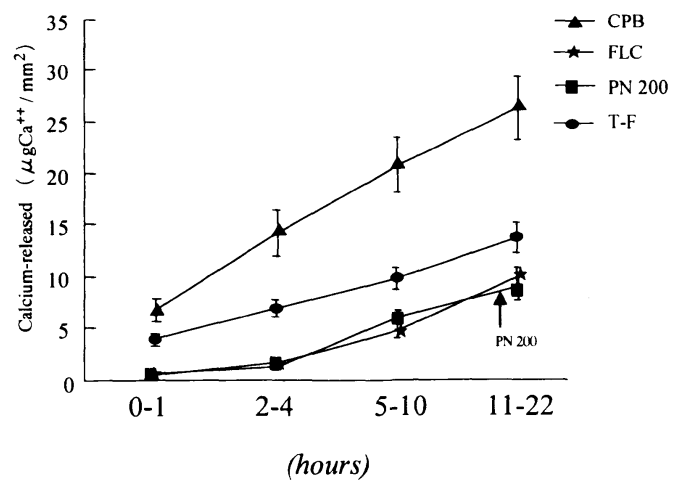

Fig. 4 Amount of calcium released from an enamel plate measured with an atomic absorption spectrophotometer.

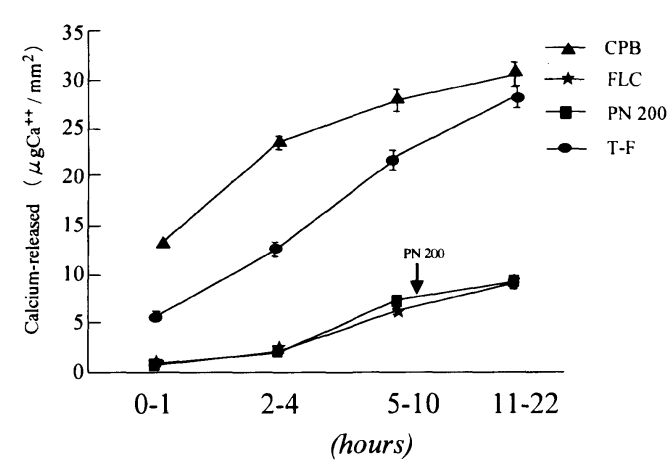

Fig. 5 Amount of calcium release from a dentin plate measured with an atomic absorption spectrophotometer. 


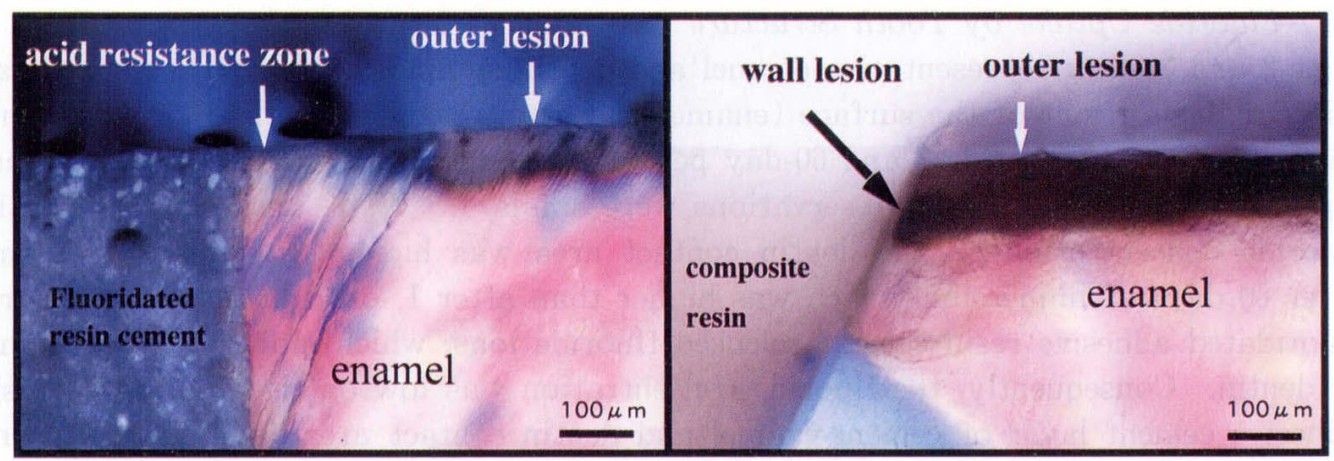

Fluoridated adhesive resin cement (PN 200)

Conventional composite resin bonding system (CPB)

Fig. 6 Demineralized enamel wall observed by polarized light microscopy. Cervically restored teeth after immersion in distilled water for 60 days, were treated with acetic acid-sodium acetate buffer for 12 hours.

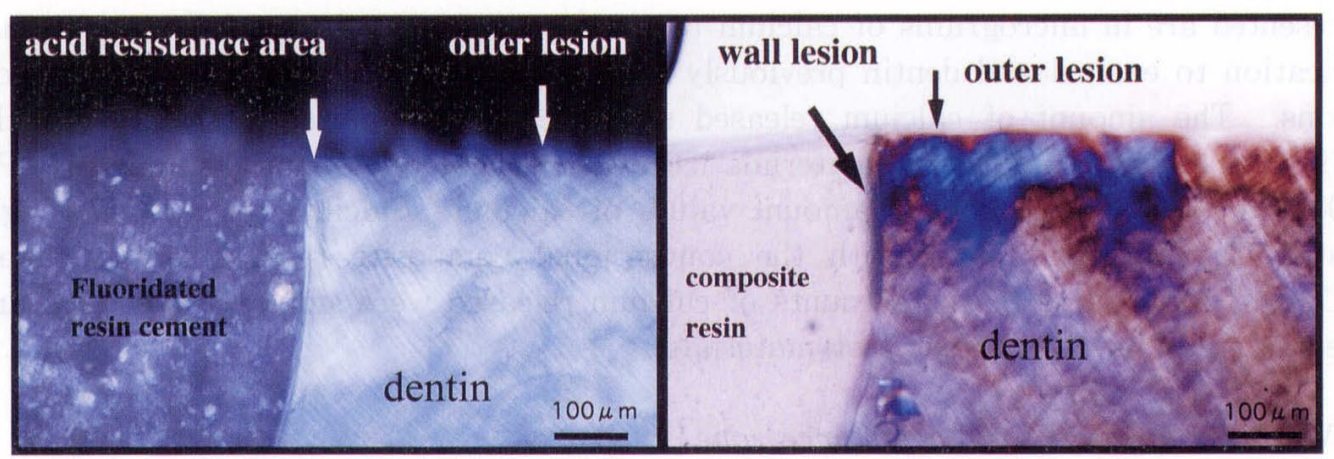

Fluoridated adhesive resin cement (PN 200)

Conventional composite resin bonding system

(CPB)

Fig. 7 Demineralized dentin wall observed by polarized light microscopy.

Cervically restored teeth after immersion in distilled water for 60 days, were treated with acetic acid-sodium acetate buffer for 12 hours.

Enamel and dentin samples show findings of the outer lesion (tooth structure outer margins of restoration) and wall lesion were compared with control samples (tooth structure samples of $\mathrm{CPB}$ ). Observation showed that the acid resistance zone of the PN 200 was wider than control samples in both enamel and dentin.

\section{DISCUSSION}

The findings of this study suggest several significant factors. Namely, fluoride release and fluoride uptake by tooth structures was higher in the fluoridate adhesive resin cement than fluoride-releasing glass ionomer cement or fissure sealant. The findings showed the important enhancement of the tooth structures acid resistance by 
the fluoridate material.

The findings of the present study clearly showed that fluoridate adhesive resin cement released fluoride to it's surroundings in vitro as detected by the fluoride ion selective electrode. The amount of fluoride released was highest in first 24 hours rather than any other period and suggested features which were fluoride releasing over the long-term, showed similar releasing patterns of fluoride as glass ionomer cement. This could be due to the presence of some fillers of the sodium fluoride in the composition of the fluoridate adhesive resin cement. Usually, fluoride releasing materials contain fluoride silica, fluoride aluminum, fluoride calcium and fluoride sodium fillers (e.g. glass ionomer cement) or fluoride releasing polymer (e.g. sealant ${ }^{6)}$. Fluoride release is easier and higher from materials which contained sodium fluoride fillers than polymer materials or glass ionomer cement ${ }^{8)}$. The characteristics of sodium fluoride filler are unknown and are business secret of the manufacturers, but the filler of sodium fluoride was a pre-treated inorganic compound which breaks into pieces and is characteristic of sodium which easily soluble in water. Therefore, fluoridate adhesive resin cement easily releases fluoride ions.

Many studies have shown the ability of glass ionomer cement restorations to increase fluoride content in adjacent enamel ${ }^{11-12)}$. In the present study areas of enamel and dentin adjacent to fluoridate adhesive resin cement restoration exhibited fluoride uptake by tooth structures. The characteristic of fluoride uptake was higher by dentin than enamel over the 60-day period and was greater than the 1 and 7-day periods.

Fluoride uptake by dentin was easier due to the following properties of dentin over enamel: a) Presence of dentinal tubules, b) Presence of collagen fibers, c) Dentin apatite crystals are smaller in size (1/10 of that of the enamel crystal) and lower in density, d) Dentin contains more water than enamel which is an important property for fluoride uptake. Fluoridate materials are needed for some water primers. To release fluoride the water becomes a medium for the fluoride ion. Enamel structures prefer a dry tissue when compared with moist dentin tissue. If margins of restorations have microscopic gaps between the cavity wall and the composite resin, fluoride release and uptake by tooth tissues may be easier, and more able to prevent secondary caries on around the restoration area.

An acidic buffered solution (acetic acid sodium buffer, $0.2 \mathrm{M}, \mathrm{pH} 4.5$ ) was used in the present study, to help clarify the influence of tooth structure acid resistance with fluoridate adhesive resin cement, which does not stimulate the oral environment where the $\mathrm{pH}$ tends to fluctuate. The results of this test showed the influence of acid resistance of the enamel and dentin samples adjacent to the fluoridate material immersed in water. Plots of the amount of calcium released after acid operated on the enamel and dentin samples adjacent to the fluoridate material, showed a lower amount of calcium released compared with control samples (Figs. 4 and 5). Therefore, the anti-caries efficacy would last longer for the enamel or dentin when using the fluoridate material for cavity restoration and it possibly has a greater influence on enamel than dentin as indicated by the anti-caries effect. 
However, fluoridate materials permitted rapid and consistent formation of outer lesions and inhibition zones as shown in Figs. 6 and 7. Considerable research has been carried out investigating demineralization, remineralization and fluoride uptake by enamel and dentin ${ }^{13-16)}$.

There is a high possibility for the presence of caries around margins of restorations, application of fluoridated adhesive resin cement will lower this possibility and prevent secondary or initial caries around the margins of the restorations in both enamel and dentin. Further, the studies need to be verified using in vivo examination.

\section{REFERENCES}

1) Skartveit, L., Tveit, A. B., Totdal, B., Ovrebo, R. and Raadal, M.: In vivo fluoride uptake in enamel and dentine from fluoride-containing materials, $J$ Dent Child 57:97-100, 1990.

2) Ten Cate, J. M. and Van Duinen, R. N.: Hypermineralization of dentinal lesions adjacent to glass-ionomer cement restorations, J Dent Res 74:1266-1271, 1995.

3) Forss, H.S.: Prevention of enamel demineralization adjacent to glass ionomer filling materials, Scand J Dent Res $98: 173-178,1990$.

4) Griffin, E., Donly, K. J. and Erickson, R.: Caries inhibition by fluoride-releasing liners, Am J Dent 5 : 293-295, 1992.

5) Mathis, R.S. and Ferracane, J. L.: Properties of glass-ionomer/resin-composite hybrid material, Dent Mater $5:$ 355-358, 1989.

6) Momoi, Y. and McCabe, J. F.: Fluoride release from light-activated glass ionomer restorative cements, Dent Mater 9 : 151-154, 1993.

7) Kawai, K., Heaven, T.J. and Retief, D. H.: In vitro dentine fluoride uptake from three fluoride-containing composites and their acid resistance, J Dent 25 : 291-296, 1997.

8) Donly, K. J. and Gomez, C.: In vitro demineralisation of enamel caries at restoration margins utilizing fluoride-releasing composite resin, Quintessence Int 25 : 355-358, 1994.

9) Cooley, R. L., McCourt, J.W. and Huddleston, A. M.: Evaluation of a fluoridecontaining sealant by SEM, microleakage and fluoride release, Pediatr Dent 12:38-42, 1990.

10) Tanaka, M., Ono, H., Kadoma, Y. and Imai, Y.: Incorporation into human enamel of fluoride slowly released from a sealant in vivo, J Dent Res 66 : 1591-1593, 1987.

11) Retief, D. H. and Bradley, E. L.: Denton, J. C. et al.: Enamel and cementum fluoride uptake from a glass ionomer cement, Caries Res $18: 250-257,1984$,

12) Arends, J., Schuthof, J. and Jongebloed, W. G.: Lesion depth and microhardness indentation on artificial white spot lesions, Caries Res 14:190-195, 1980.

13) Donly, K. J.: Enamel and dentin demineralization inhibition of fluoride-releasing materials, J Dent $7: 275-278,1994$.

14) Forsten, L.: Resin-modified glass ionomer cement: fluoride release and uptake, Acta Odontol Scand $53: 222-225,1995$.

15) Hotz, P.R.: Experimental secondary caries around amalgam, composite and glass ionomer cement fillings in human teeth, Helvetica Odontologica Acta $23: 9-39,1979$.

16) Swartz, M. L., Phillips, R.W. and Clark, H.E., et al.: Fluoride distribution in teeth using silicate model, $J$ Dent Res 59 : 1596-1603, 1980. 